\title{
An Analysis of the Water Conflicts and Solutions in the Leapfrog Development of Xinjiang, China
}

\author{
Wenlong Zuo, Shouyang Wang, Xi Chen, Yanfang Qin, and Jichang Dong
}

\begin{abstract}
Water shortage is the primary factor to constrain Xinjiang's socio-economic development. This paper starts from the relationship between Xinjiang's water consumption and socio-economic development, and selects optimal fitting functions to predict the probable water consumptions in the future decade. The results show total water consumption in Xinjiang rose steadily from 1997 to 2010 , and the irrigation section occupied a great share $(>90 \%)$. The total water consumption has a high correlation coefficient at 0.924 with per capita GDP and the predicted value is $583.84 \times 10^{8} \mathrm{~m}^{3}$ in 2020 , with a $48.76 \times 10^{8} \mathrm{~m}^{3}$ increase compared to 2010 . Water consumption in manufacture and construction also has high correlation coefficient with the secondary industrial GDP and this water share could be $27.68 \times 10^{8} \mathrm{~m}^{3}$ in 2020 with an increase $14.08 \times 10^{8} \mathrm{~m}^{3}$. Furthermore, considering the increasing ecological water need, the only effective way to achieve the goals of Xinjiang's leapfrog development is to reasonably allocate water resources and improve the water use efficiency. Thus a set of scientific strategies are sketched for Xinjiang's water exploitation and utilization, which is of important practical significance and reference value to both achieve Xinjiang's Leapfrog-development and positive circle the social-economic-ecological development.
\end{abstract}

Index Terms-Water consumption, sustainable development, conflicts and solutions, Xinjiang's leapfrog development.

\section{INTRODUCTION}

Xinjiang has a typical arid and semi-arid environment. Due to the barriers formed by the Altai Mountains on the north and the Kunlun Mountains on the south, water vapor from Atlantic Ocean and Indian Ocean has little effect on climatic conditions. Therefore, it has scarce precipitation, strong evaporation, extremely uneven distribution of water resources, and sharp temperature changes. The average annual rainfall is about $147 \mathrm{~mm}(20-100 \mathrm{~mm}$ in southern Xinjiang and 100-300 mm in northern Xinjiang), with $70 \%$ of the annual rainfall happens from May to August, while the annual evaporation is up to $1000-4500 \mathrm{~mm} \mathrm{[1],} \mathrm{[2].} \mathrm{Such}$ geographical, climate and water conditions determine that water is the lifeline of people's survival and development in Xinjiang and the blood of the regional economy and ecological environment, thus, a unique "desert-oasisirrigated agriculture' ecological and socio-economic system

Manuscript received November 10, 2012; revised January 15, 2013.

This work was supported in part by the National Natural Science Foundation of China under Grant 41101429.

Wenlong Zuo, Shouyang Wang, and Jichang Dong are with the University of Chinese Academy of Sciences, Beijing, 100190 China (e-mail: Warren_Zuo@hotmail.com, sywang@amss.ac.cn, jcdonglc@gscas.ac.cn).

Xi Chen and Yanfang Qin are with the Xinjiang Institute of Ecology and Geography, Chinese Academy of Sciences, Urumqi, 830011, China (e-mail: chenxi@ms.xjb.ac.cn, yanfqin@live.cn). has formed [3].

"Oasis appears along with water, desert forms because of drought", the local people have inhabited by the water for a long history, and the population growth and economic development is closely related to water. Nearly a semicentury, with the continuously accelerated development of Xinjiang's society and economy, the industrial, agricultural and domestic demand of water has rapidly been increasing. Water shortage, water pressure, and the consequent ecological environment deteriorating become to be critical social issues to be solved and the "bottleneck" that restricts further development of economy and society [4].

Currently, the Chinese government attaches great importance to the development of Xinjiang, and increases the supports and investments in Xinjiang. The concept of "Xinjiang's leapfrog development" means to utilize the whole state's power to promote the great-leap-forward development and stability of Xinjiang, which provides a golden opportunity and a powerful driving force for Xinjiang's development, at the same time the natural resources and environment will face unprecedented pressure [5], [6]. As one of the most basic natural resources and productivity factors of social and economic development in Xinjiang, water plays a decisive role on the scale of economic development, the distribution of productive forces and social development. The congenital deficiency and improper utilization of water resources have seriously constrained the further development of Xinjiang. Only the water problems were solved firstly, the poverty alleviation, socio-economic development and the improvement of ecological environment could proceed to the next. Hence, under the new situation of leapfrog development in Xinjiang, how to promise the coordination of water use in producing, living and ecological protecting has become the primary problem.

In this paper, we use the data from "Xinjiang water resources bulletin" (1997-2010) and "Xinjiang Statistical Yearbook" (1998-2011), to reveal the relationships between water consumptions and socio-economic growing in Xinjiang, and to predict the gap between water supply and demand in the second decade of the 21 st century. Then according the water demand of each industry, we explore a reasonable allocation of water resources and propose several countermeasures which are beneficial to the whole social-economic-ecological sustainable development.

\section{The WATER Utilization Changed With SOCIO-ECONOMIC DEVELOPMENT OF XINJIANG}

According to the previous results of the comprehensive evaluation and planning researches of the water resources in 
Xinjiang [7], the average annual total precipitation is about $2544 \times 10^{8} \mathrm{~m}^{3}$, and the indigenous quantity of water is $832 \times$ $10^{8} \mathrm{~m}^{3}$, in which the amount of surface water resources is 789 $\times 10^{8} \mathrm{~m}^{3}$, the groundwater is $503 \times 10^{8} \mathrm{~m}^{3}$, and the unrepeated amount is $43 \times 10^{8} \mathrm{~m}^{3}$. At present, the average inbound water is $90 \times 10^{8} \mathrm{~m}^{3}$, while the outbound number reaches $232 \times 10^{8} \mathrm{~m}^{3}$, thus the total available water resources of Xinjiang is $690 \times 10^{8} \mathrm{~m}^{3}$. So the average water-producing coefficient is 0.327 , and the average water-producing modulus is $5.062 \times 10^{4} \mathrm{~m}^{3} / \mathrm{km}^{2}$, which means a lowest water-producing ability in China.

TABLE I: THE WATER CONSUMPTION AND SOCIO-ECONOMIC DEVELOPMENT IN XINJIANG FROM 1997 TO 2010

\begin{tabular}{|c|c|c|c|c|c|}
\hline Year & $\begin{array}{c}\text { Per } \\
\text { Capita } \\
\text { GDP } \\
(\mathrm{CNY})\end{array}$ & $\begin{array}{c}\text { Total } \\
\text { WC }^{\mathrm{a}} \\
\left(10^{8} \mathrm{~m}^{3}\right)\end{array}$ & $\begin{array}{c}\text { WC in } \\
\text { Agriculture } \\
\left(10^{8} \mathrm{~m}^{3}\right)\end{array}$ & $\begin{array}{c}\text { WC in } \\
\text { Manufacture } \\
\text { and } \\
\text { Construction } \\
\mathrm{b} \\
\left(10^{8} \mathrm{~m}^{3}\right)\end{array}$ & $\begin{array}{c}\text { WC in } \\
\text { Services and } \\
\text { Residential } \\
\text { Living }^{\mathrm{c}} \\
\left(10^{8} \mathrm{~m}^{3}\right)\end{array}$ \\
\hline 1997 & 5848 & 457.25 & 442.66 & 8.15 & 6.41 \\
\hline 1998 & 6174 & 449.05 & 414.74 & 11.34 & 22.97 \\
\hline 1999 & 6443 & 485.88 & 463.82 & 10.58 & 11.49 \\
\hline 2000 & 7372 & 480.00 & 453.20 & 10.89 & 15.85 \\
\hline 2001 & 7945 & 487.15 & 463.85 & 9.64 & 13.66 \\
\hline 2002 & 8457 & 475.00 & 449.33 & 10.18 & 15.52 \\
\hline 2003 & 9828 & 494.40 & 457.70 & 8.28 & 28.49 \\
\hline 2004 & 11337 & 496.40 & 459.74 & 8.01 & 28.65 \\
\hline 2005 & 13108 & 508.30 & 469.60 & 9.97 & 28.74 \\
\hline 2006 & 15000 & 513.73 & 471.44 & 10.59 & 31.70 \\
\hline 2007 & 16999 & 517.74 & 478.44 & 10.79 & 28.51 \\
\hline 2008 & 19797 & 528.22 & 487.78 & 11.43 & 29.01 \\
\hline 2009 & 19942 & 530.90 & 492.80 & 11.78 & 26.33 \\
\hline 2010 & 25057 & 535.08 & 495.95 & 13.60 & 25.53 \\
\hline
\end{tabular}

WC: Water Consumption by human society, except the natural share of ecological system, hereafter referred as the same.

b The indicators for summarizing the parts of water use in manufacture, construction, services and residential living has been changed since 2003.

This part contains water use sharing in services, residential living and ecological environment (specifically referring to artificial ecological water), some indicators for this part had been summarized in the second manufacture and construction part before 2003 .

\section{A. Socio-Economic Development}

Generally, the per capita GDP (gross domestic product) can accurately reflect the overall level of regional economic development level, and is also the core indicator for building the well-off society in all-round way. From Table I, the per capita GDP grew almost 4 times from 1997 to 2010. Due to the limitation of the total water resources available, the rapidly growing share of water demand for socio-economic system occupied a part of the share for natural environment, which had caused serious stress for the environment and resulted in aggravating perhaps irreversible ecological damage.

\section{B. Water Consumption Changes}

From the view of Table I, the exploitation and utilization of water resources in Xinjiang was rising steadily year by year. From 1997 to 2010, the amount of total water consumption has been on the rise from $457.25 \times 10^{8} \mathrm{~m}^{3}$ to $535.08 \times 10^{8} \mathrm{~m}^{3}$, in which the section in agriculture occupies quite a great share. More than $90 \%$ of water has been used to irrigate the farmlands, and this section of water consumption was also increasing year by year together with the total amount. Looking up the facts of Xinjiang's development, the growth of agricultural water are inseparable with the increase of cultivated land area, which has expanded from $3.229 \times 10^{6}$ ha to $5.123 \times 10^{6}$ ha in $1997-2010$, with an increase of $58.7 \%$.

Besides, the other two sections are relatively stable. Due to a new statistical standard were used for "Xinjiang water resources bulletin" in 2003, the changes before that do not need to be considered. After the year 2003, the second part of water consumption in manufactures and constructions has a gradual growth, while the left part has a fluctuating change.

\section{Correlation BETWEen WATER UTILIZATION AND SOCIO-ECONOMIC DEVELOPMENT OF XINJIANG}

Referring to the targets of Xinjiang's Leapfrog Development, the regional per capita GDP in 2015 should reach the average national level and the overall socio-economic development level should achieve the requirements of all-round well-off society in 2020. On the other hand, goals in the 12th Five-Year Plan and leapfrog development of Xinjiang shows that the cultivated land area will remain the same in the future, and then continuously improved irrigation techniques will reduce agricultural water. Then under the premise of water consumption in services and residential living roughly steady, the main growth of water use should be embodied in the manufacture and the construction.

To determine the relationship between socio-economic growth and water consumption in Xinjiang, we select the total water consumption and the secondary water share (consumption in manufacture and construction) as the dependent variable, select per capita GDP and secondary industrial GDP (created by manufacture and construction) as the independent variable to map two-dimensional scatter diagrams, and then use linear, quadratic polynomial, exponential, logarithmic and power function to fit the relationship in turn and calculate the corresponding determination coefficients $\mathrm{R}^{2}$ respectively.

\section{A. Total Water Consumption and Per Capita GDP}

In accordance with the data of Table I, it can be calculated that the correlation coefficient between total water consumption and per capita GDP is 0.924 , showing a quite significant correlation between the two indicators.

As shown by Fig. 1 and Table II, all the fitting functions calculated by different models have high determination coefficients $(>0.8)$, also indicates a highly relativity between the total water consumption and per capita GDP. Furthermore, the scatterplot Fig. 1 is more in line with a logarithmic curve, which could also be proved from the determination coefficients $\mathrm{R}^{2}$ in Table II. Combined with the facts of Xinjiang's development, it could be considered that the economic development needs more water resources while the continuous improved technologies to utilize water has also lowered the amount of water needed to make each extra unit of GDP in the meantime, at last leading to a steady state of water use under certain conditions.

\section{B. Secondary Water Share and Secondary Industrial GDP}

Due to a changed summarizing standard, the correlation coefficient between secondary industrial GDP and water 
consumption in manufacture and construction is 0.972 by calculating data after 2003 in Table I and "Xinjiang Statistical Yearbook".

The scatterplot of Fig. 2 indicates a progressively increasing relationship between the secondary industrial GDP and the water consumption share in manufacture and construction, and the fitting functions in Table II calculated by different models also have relative high determination coefficients. Comparative referring the characteristics of scatterplot and determination coefficients, the relation curve of secondary industrial GDP and the secondary water share is more like the rising part of a parabolic curve.

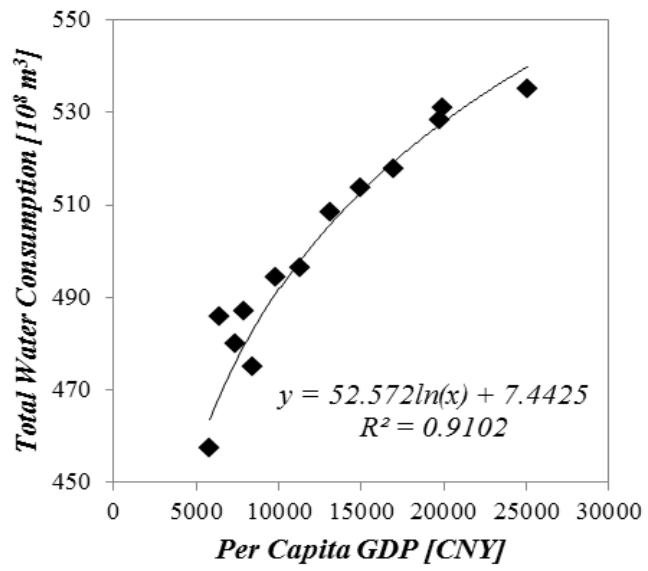

Fig. 1. Scatterplot to relate total water consumption and per capita GDP

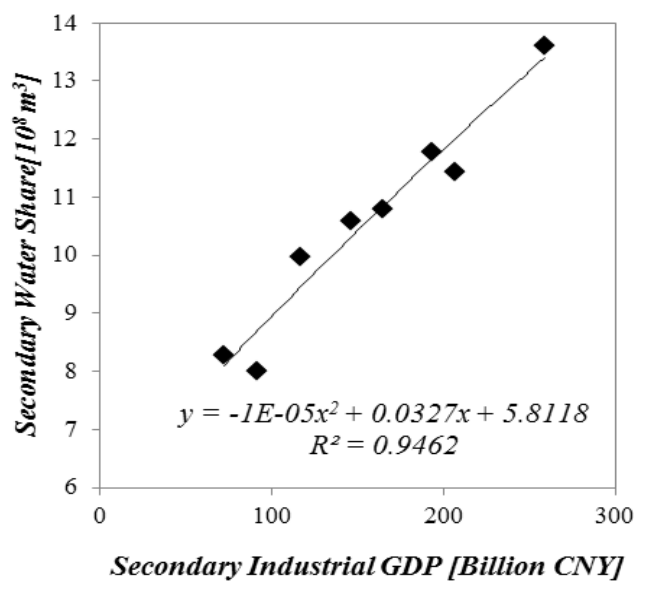

Fig. 2. Scatterplot to relate secondary water share and secondary industrial GDP

TABLE II: THE FITTING FUNCTIONS AND DETERMINATION COEFFICIENTS R²

\begin{tabular}{lcccc}
\hline \hline & \multicolumn{2}{c}{ Total WC - Per Capita GDP } & \multicolumn{2}{c}{$\begin{array}{c}\text { Secondary WC - } \\
\text { Secondary Industrial GDP }\end{array}$} \\
\cline { 2 - 5 } & \multicolumn{1}{c}{$\mathrm{y}-\mathrm{x}$} & $\mathrm{R}^{\mathbf{2}}$ & $\mathrm{y}-\mathrm{x}$ & $\mathrm{R}^{2}$ \\
\hline Linear & $\mathrm{y}=0.004 \mathrm{x}+447.03$ & 0.8547 & $\mathrm{y}=0.0284 \mathrm{x}+6.115$ & 0.9455 \\
\hline $\begin{array}{l}\text { Quadratic } \\
\text { Polynomial }\end{array}$ & $\begin{array}{c}\mathrm{y}=-2 \mathrm{E}-07 \mathrm{x}^{2}+0.0096 \mathrm{x} \\
+414.59\end{array}$ & 0.9085 & $\begin{array}{c}\mathbf{y}=\mathbf{- 1 E - 0 5 x 2 + 0 . 0 3 2 7} \\
\mathbf{x + 5 . 8 1 1 8}\end{array}$ & $\mathbf{0 . 9 4 6 2}$ \\
\hline Exponential & $\mathrm{y}=448.96 \mathrm{e}^{8 \mathrm{E}-06 \mathrm{x}}$ & 0.8373 & $\mathrm{y}=6.8139 \mathrm{e}^{0.0027 x}$ & 0.9249 \\
\hline Logarithmic & $\mathbf{y = 5 2 . 5 7 2} \ln (\mathbf{x})+\mathbf{7 . 4 4}$ & $\mathbf{0 . 9 1 0 2}$ & $\begin{array}{c}\mathrm{y}=4.0769 \ln (\mathrm{x})-9.721 \\
4\end{array}$ & 0.9257 \\
\hline Power & $\mathrm{y}=185.03 \mathrm{x}^{0.106}$ & 0.8990 & $\mathrm{y}=1.4583 \mathrm{x}^{0.3952}$ & 0.9329 \\
\hline \hline
\end{tabular}

\section{WATER CONFLICTS IN XINJIANG'S LEAPFROG DEVELOPMENT}

In the $12^{\text {th }}$ Five-Year Plan of Xinjiang Uygur Autonomous
Region, the average annual growth rate of GDP and population will be controlled as $>10 \%$ and $<11 \%$ from 2010 to 2015 , then the per capita GDP works out at $37878 \mathrm{CNY}$ in 2015. If the ratios remained constant until 2020, then the GDP of total autonomous region could be about $57756 \mathrm{CNY}$ in 2020. Additionally, the average annual growth rate of manufacture and construction will be controlled no less than $17 \%$. If the rate keeps stable in the next decade, counting in base 259.215 billion CNY in 2010, the secondary GDP created by manufacture and construction will be $427.53 \mathrm{CNY}$ in 2015 and 937.33 billion CNY in 2020.

When these values are fed into the respectively optimal formulas of Table II, a set of water consumption values could be obtained.

TABLE III: WATER CONSUMPTIONS YIELDED BY OPTIMAL FITTING FUNCTIONS

\begin{tabular}{lcclc}
\hline \hline & \multicolumn{2}{c}{ Predicted Total WC } & \multicolumn{2}{c}{ Predicted Secondary WC } \\
\cline { 2 - 5 } & $\mathrm{x}(\mathrm{CNY})$ & $\mathrm{y}\left(10^{8} \mathrm{~m}^{3}\right)$ & $\begin{array}{c}\mathrm{x}(\text { billion } \\
\text { CNY })\end{array}$ & $\mathrm{y}\left(10^{8} \mathrm{~m}^{3}\right)$ \\
\hline In 2015 & 37878 & 561.66 & 427.53 & 17.96 \\
In 2020 & 57756 & 583.84 & 937.33 & 27.68 \\
\hline \hline
\end{tabular}

\section{A. Predicted Total Water Consumption}

As mentioned before, the relationship function between total water consumption and per capita GDP is more in line with a logarithmic curve $\left(\mathrm{R}^{2}=0.9102\right)$, the corresponding yielded total water consumption values were: $561.66 \times 10^{8}$ $\mathrm{m}^{3}$ in 2015 , which could reach the level of Xinjiang's $12^{\text {th }}$ Five-Year Plan and have an increase of $26.58 \times 10^{8} \mathrm{~m}^{3}$ compared with it in 2010; $583.84 \times 10^{8} \mathrm{~m}^{3}$ in 2020 and an increase of $48.76 \times 10^{8} \mathrm{~m}^{3}$ compared to 2010 , if with a consistent development level.

\section{B. Predicted Water Consumption in Manufacture and Construction}

When choosing the quadratic polynomial model due to its highest determination coefficient $\left(\mathrm{R}^{2}=0.9462\right)$, the water share in manufacture and construction could be: $17.96 \times 10^{8}$ $\mathrm{m}^{3}$ when it reached Xinjiang's $12^{\text {th }}$ Five-Year planning level in 2015 , with a demand increase of about $4.36 \times 10^{8} \mathrm{~m}^{3}$ compared to $2010 ; 27.68 \times 10^{8} \mathrm{~m}^{3}$ in 2020 and a compared increase $14.08 \times 10^{8} \mathrm{~m}^{3}$ with 2010 , if the development level remained the same.

\section{Additional Environmental Water Consumption}

Furthermore, the requirements of an all-round well-off society are not only in regard to the socio-economic system, but also include a set of corresponding conditions about the ecological environment we live in. Owing to the large-scale land reclamation and extensive irrigation in nearly a half century, Xinjiang is facing severe ecological problems, the evolution of natural ecology has shown signs as "two expansions and one shrink": the deserts and oases were expanding while the transition zones between them were decreasing; additionally, the artificial oasis area had an expansion development while the natural oasis area actually was declining.

According to previously reports and findings of relevant departments and other scholars, it is necessary to restore at least about $1.4 \times 10^{4} \mathrm{~km}^{2}$ natural oasis to maintain the 
stability of the existing artificial oasis in Xinjiang, which means an increased $25 \times 10^{8} \mathrm{~m}^{3}$ water to compensate the ecological environment compared with the status quo [7].

For the water resources in Xinjiang, the current exploiting level has reached the limit of available amount, even diverted the share of natural ecosystems for agricultural irrigating. Besides, through improving irrigation techniques to reduce the water loss in agricultural processes has substantially reduced the part compensating to ecological environment, through which is unable to increase available water. To achieve the goals of Xinjiang's leapfrog development in the future decade and meet the increasing water demand for industrial growth and ecological restoration, the only effective way is to reasonably allocate water resources in different departments, reduce the agricultural water through effective measures, and improve the water use efficiency.

\section{SOLUTIONS AND COUNTERMEASURES}

\section{A. Industrial Structure Adjustment}

Xinjiang is net output region of major agricultural products (such as cotton), oil and gas in China. Taking advantages of local resources has been promoting the economic development of Xinjiang, but such an economic structure is built on the basis of high water consumption. The root cause of unreasonable water structure and low water use efficiency is led by the economic structure of high water consumptive agriculture, resource extraction and primary processing industries.

Therefore, in agriculture, it is of crucial importance to change the development mode only depending on expanding the irrigation area and to develop a water-saving, efficient, productive, characteristic, ecological agriculture system, so as to control the agricultural water consumption in around $450 \times 10^{8} \mathrm{~m}^{3}$. The irrigation area should be combined with the resources balance of water and soil, adjusted and comprehensive arranged to local conditions, under the premise of reasonably arranging ecological water and ensuring industrialization and urbanization water. Generally, some regions with an overall more than $50 \%$ water consumption in socio-economic system should diminish the existing irrigated area and return the saved water to ecology; while regions has potential to water utilization and less land for more people could moderately develop a small amount of irrigation area, but epitaxial expansion must be stopped. To achieve the growth of agricultural products, the added value must be improved by developing the deep processing industries with high-tech content and high level. Finally, a sharp decline of the agricultural water depends on a substantial increase of land productivity and efficient resource utilization, which could be reached by adjusting the planting structure, appropriately reducing the planting scale of high water consumptive crops such as cotton, and optimizing the cultivation mode.

In manufacture, a more effective way of leapfrog development is to give full play to its own advantages on regional mineral resources, through optimizing structure, extending the industrial chains, speeding up resource exploitation and transformation, and improving added value.
In the meantime, water saving could be achieved by improving the recycling rate of water resources and reducing water pollution and waste. Moreover, new industries regarding to new energies and materials, conservation and environmental protection, biological pharmacy usually have benefits of water saving, which provides feasibility for the maximal break of industrial output with minimum water consumption.

In services, industries such as trade and tourism need less water but producing high GDP. The current services output shares total amount of GDP only about $35 \%$, while the ratio should be at least $50 \%$ to achieve the objective of all-round well-off society.

\section{B. Water Conservancy Projects}

To meet the socio-economic water needs and ensure sustainable use of water resources, the key of water conservancy work in Xinjiang is water conservation. The future agriculture in Xinjiang inevitably will go connotative development road of improving unit efficiency of agricultural production, and it is essential to promote water-saving irrigation, improve saline-alkali soil, and control groundwater exploitation according to local conditions.

Secondly, due to the extremely uneven spatial and temporal distribution of water resources in Xinjiang, the regional engineering projects of water resources allocation is essential. In order to further improve the water utilization, reduce mountain floods and water loss in the plain areas, reservoirs should be built in the mountain pass of major rivers and composed the water allocation system highly joint with plain reservoirs and diversion works.

Finally, as a part of water resources, the utilization of unconventional water like snow, saline groundwater is currently very low. The continuous development of water exploitation and utilization technologies makes this part of water also used for agricultural and industrial producing, thus the corresponding supporting and conservancy projects should be gradually constructed and improved.

\section{Water Resource Management}

A sound management system is the premise of optimal allocation and management of water resources, which should take watershed as a unit, scientifically formulate the amount of ecological water and total economic water, then allocate into each administrative region within the watershed and each water use department, have clear management agencies to execute work in strict accordance with the river water resources allocation and scheduling plans, implement quota management of water supply to promote water conservation and efficiency. At last, the water regulation system and the water price reform should be completed and deepen further. The economic leverage also could be used for promoting agricultural water saving under the protection of the regulations and taking local conditions into consideration.

Therefore as long as we persist in scientific development and coordinate the relationship between socio-economic development and ecological environmental protection, Xinjiang's leapfrog development certainly will be achieved with the support of sustainable water utilization. 


\section{REFERENCES}

[1] R. S. Zhong, X. H. Dong, and Y. J. Ma, "Sustainable water saving: new concept of modern agricultural water saving, starting from development of Xinjiang's agricultural irrigation over the last 50 years," Irrigation and Drainage, vol. 58, pp. 383-392, Feb. 2009.

[2] X. L. Zhang and J. Lei, "Trend of urban system structure under the restriction of water and land resources in Xinjiang," Chinese Science Bulletin, vol. 511, pp. 179-188, Aug. 2006.

[3] X. Wang and Y. Z. He, "The measurement model and an empirical study of agricultural competitiveness of Xinjiang corps," Journal of Xinjiang University of Finance and Economics, vol. 45, pp. 11-14, June 2011

[4] M. J. Deng, "Research and thinking on water resources in Xinjiang," Quaternary Sciences, vol. 30, pp. 107-114, Jan. 2010.

[5] M. J. Deng, X. Q. Li, A. H. Long, Y. Zhang, and D. X. Wang, "Regulation of supply and demand structure of the water resources and support economic and social leap-forward development of protection measures," Arid Land Geography, vol. 34, pp. 379-390, June 2011.

[6] Y. X. Ye and B. Y. He, "Environmental protection in Xinjiang Great-Leap-Forward Development," Northern Environment, vol. 23, pp. 14-16, Sept. 2011.

[7] N. Baikli, W. Z. Wang, and E. W. Shi, Strategy Research Report for Sci-tech Supporting and Leading Xinjiang's Leapfrop Development, 1st ed. Beijing, China: Science Press, Ch. 9, pp. 208-209, 2012.

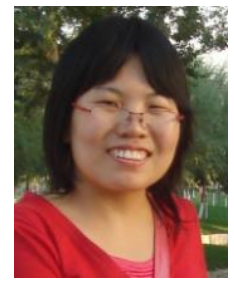

Yanfang Qin was born on June 25, 1984 in Xinxiang, China. In 2002, she attended the College of Environment and Planning of Henan University located in Kaifeng and received the B.S. degree in geographic information systems after 4 years study. In 2006, she began to study for a master degree in Xinjiang Institute of Ecology and Geography (XIEG), Chinese Academy of Sciences, and was selected for the Ph.D. in advance in 2008 due to her excellent performance. In June of 2012, she completed her doctoral dissertation in Urumqi and was awarded the Ph.D. in cartography and geographic information systems. In the past 6 years in XIEG, she was dedicated to the study of remote sensing in arid ecological and hydrologic problems. Some of the findings have been published, such as: Natural Resources of Arid Metropolitan Urumqi (Urumqi, China: Xinjiang Art and Photography Publishing House, 2011), Research on Xinjiang water resources development and optimized configuration (Urumqi, China: Journal of the party school of CPC Urumqi municipal committee, 2008), Using GPR to sound the spatial and temporal distributions of dune surface soil water contents before and after snowmelt in the early spring (Lanzhou, China: Journal of Glaciology and Geocryology, 2012). Currently she is researching on the ground-penetrating radar for measuring soil moisture in arid area and very interested in the rational allocation of water resources in Xinjiang Uygur Autonomous Region of China. 